This article was published in Environmental Pollution, 202, 7-16, 2015

http://dx.doi.org/10.1016/j.envpol.2015.03.009

\title{
1 Particulate matter in rural and urban nursery schools in Portugal
}

2 R.A.O. Nunes, P.T.B.S. Branco, M.C.M. Alvim-Ferraz, F.G. Martins, S.I.V. Sousa*

3 LEPABE - Laboratory for Process Engineering, Environment, Biotechnology and Energy,

4 Faculty of Engineering, University of Porto, Rua Dr. Roberto Frias, 4200-465, Porto, Portugal

5

$6 *$ Corresponding author:

$7 \quad$ Telephone: +351225082262

$8 \quad$ Fax: +351225081449

$9 \quad$ E-mail address: sofia.sousa@fe.up.pt

10 Postal address: Rua Dr. Roberto Frias, 4200-465, E215, Porto, Portugal 


\section{Abstract}

Studies have been showing strong associations between exposures to indoor particulate matter (PM) and health effects on children. Urban and rural nursery schools have different known environmental and social differences which make their study relevant. Thus, this study aimed to evaluate indoor PM concentrations on different microenvironments of three rural nurseries and one urban nursery, being the only study comparing urban and rural nurseries considering the $\mathrm{PM}_{1}, \mathrm{PM}_{2.5}$ and $\mathrm{PM}_{10}$ fractions (measured continuously and in terms of mass). Outdoor $\mathrm{PM}_{2.5}$ and $\mathrm{PM}_{10}$ were also obtained and $\mathrm{I} / \mathrm{O}$ ratios have been determined. Indoor PM mean concentrations were higher in the urban nursery than in rural ones, which might have been related to traffic emissions. However, I/O ratios allowed concluding that the recorded concentrations depended more significantly of indoor sources. WHO guidelines and Portuguese legislation exceedances for $\mathrm{PM}_{2.5}$ and $\mathrm{PM}_{10}$ were observed mainly in the urban nursery school.

Capsule: PM levels were higher in the urban nursery than in the rural ones, which might have been related to traffic emissions. Still concentrations depended more significantly of indoor sources

\section{Keywords}

Indoor air, particulate matter, nursery school, rural, urban 


\section{Introduction}

PM have been recognized by various organizations such as USEPA and WHO as a priority pollutant, having high potential to induce various adverse effects to human health such as pulmonary diseases, asthma and other respiratory problems (Stanek et al., 2011; Sousa et al., 2012a). There is also evidence that particles can cause skin, eyes, nose, throat and upper airways irritations, shortness of breath, dizziness, and allergic reactions (Sousa et al., 2012a; USEPA, 2012).

Nursery schools could be a very interesting case study because children are vulnerable to compromised Indoor Air Quality (IAQ) due to their not fully developed immune system and lungs, greater inhaled breath per unit mass, and rapid growth of their tissues and organs, which raises the possibility of higher exposure than occurs in adults (Branco et al., 2014a; Yoon et al., 2011; Pegas et al., 2012). Beyond that, children spend more time in schools (or preschools and nursery schools) than in any other indoor microenvironment besides home (Branco et al., 2014b). Although no definitive proof exists, it can be assumed that preschool students, because of their activities, are more susceptible to the adverse effects of a poor IAQ than elementary or middle school students (Hagerhed-Engman et al., 2006). Many pollutants are present in nursery schools' indoor air, but PM is the one that has attracted more interest from researchers. Particles arise in indoor air from both indoor and outdoor sources and can be affected by many factors such as particle re-suspension from activities of building occupants, cooking, heating, consumer products, building materials (carpeting, flexible flooring, paint, and plastics), furnishings and equipment (Sousa et al., 2012b). Cleaning activities, ventilation rates and dust coming from outside of the buildings (responsible for the existence of very adverse compounds in particles such as heavy metals mainly due to traffic emissions) are also important factors that determine indoor PM concentrations (Lu et al., 2014; Sousa et al., 2012b; Darus et al., 2012). 
In the last five years several studies on indoor air PM pollution have been conducted focusing on $\mathrm{PM}_{2.5}$ and $\mathrm{PM}_{10}$ in primary schools (Sousa et al. 2012b; Almeida et al., 2011). Nevertheless, studies in nursery schools are still few. As far as it is known there are only eleven studies focussing on PM in nursery schools' indoor air. Tong and Lam (2008), Darus et al. (2012) and Lu et al. (2014) investigated the concentrations and contamination of metals in PM from nursery schools in Hong Kong, Malaysia and China, respectively. The results of Tong and Lam (2008) and Darus et al. (2012) studies demonstrated that some nursery schools have high levels of heavy metals and suggested that traffic was one of their major sources. Lu et al. (2014) concluded that most samples were moderately polluted by metals and their concentrations in dust samples from nursery schools located in the old downtown were lower than in the samples from schools situated outside the town. Fromme et al. (2005), that studied elemental carbon and respirable PM in the indoor air of apartments and nursery schools as well as ambient air in Berlin, also reported a strong relationship between motorway traffic and indoor air PM concentrations. Despite the determination of metal concentrations in dust samples and evaluation of their pollution levels and health risks to children, measurements were performed only in urban context and $\mathrm{PM}_{2.5}$ and $\mathrm{PM}_{10}$ concentrations were not determined. Zuraimi and Tham (2008) conducted a cross-sectional study in nurseries in Singapore by evaluating comfort parameters, some gaseous compounds and $\mathrm{PM}_{2.5}$, having concluded that for $\mathrm{PM}_{2.5}$ concentrations, despite outdoor infiltrations, indoor sources were the main sources of PM indoor levels. Wichmann et al. (2010), that measured $\mathrm{PM}_{2.5}$, soot, $\mathrm{NO}_{2}$ and the air exchange rate in nursery schools in Sweden, Yang et al. (2009), that characterized the concentrations of different indoor air pollutants ( $\mathrm{PM}_{10}$ fraction) in Korean nursery schools, and Cano et al. (2012), that performed a similar study in Portugal (Lisboa and Porto), also concluded the same. However, in these four studies only $\mathrm{PM}_{2.5}$ or $\mathrm{PM}_{10}$ fraction were evaluated. Most recent research studies have been focusing in $\mathrm{PM}_{2.5}$ (most harmful to human health) and $\mathrm{PM}_{10}$ simultaneous, 
both usually used in international guidelines. Cano et al. (2012) also referred to this in their study. Furthermore, results showed that cleaning activities increased PM concentrations in indoor air and suggested that cooking activities could increase PM concentrations in lunch rooms. Fonseca et al. (2014) studied ultrafine particle levels in urban and rural preschools in the north of Portugal. The results demonstrated that the levels of ultrafine particles in various microenvironments of preschools were significantly different, with the lowest levels found in the classrooms and the highest ones found in lunch rooms. These results also suggested that children attending urban preschools are potentially exposed to higher levels, mainly due to the contribution of outdoor traffic-related sources and cooking activities. However, in that study, measurements were performed only during occupation periods and particle mass concentrations were not measured (only particle number was considered). Yoon et al. (2011) is the only study besides Fonseca et al. (2014) that studied both urban and rural nursery schools. They studied 71 classrooms in 17 nursery schools and searched for indoor air quality differences (several pollutants including TSP and respirable particles) between urban and rural ones, and confirmed that the PM concentrations indoors were higher than those outdoors, and also that those in urban areas were higher than in rural areas. Lack of comparative analysis between different classrooms and other environments inside the same nursery and a limited analysis to the coarser $\mathrm{PM}$ fractions as well as gravimetric sampling for 6 to $8 \mathrm{~h}$ were the major limitations of this study.

Branco et al. (2014a) studied PM concentrations ( $\mathrm{PM}_{1}, \mathrm{PM}_{2.5}, \mathrm{PM}_{10}$ and TSP) in classrooms and lunch rooms in three urban nursery schools in the city of Porto. The results confirmed that indoor sources were clearly the main contributors to indoor PM concentrations when compared with outdoor influence and the classrooms occupied by older children were found to be those with the highest concentrations, due to the PM re-suspension phenomenon. Although various fractions of PM were analysed in continuous measurements over several days and in different 
microenvironments, measurements were performed only in urban nursery schools. Following Branco et al. (2014a) study (nevertheless considering different nurseries to reinforce conclusions) and in the scope of INAIRCHILD project (Sousa et al. 2012a), this study aimed to reduce the above referred gaps, through the evaluation of indoor concentrations of particulate matter $\left(\mathrm{PM}_{1}, \mathrm{PM}_{2.5}, \mathrm{PM}_{10}\right.$ and TSP) on different indoor microenvironments (classrooms and lunch rooms) of rural nursery schools and in an urban nursery. For that, PM concentrations were compared between rural and urban nursery schools and with Portuguese legislation and WHO guidelines for IAQ and children's health. Thus, this is the only study comparing urban and rural nurseries considering the $\mathrm{PM}_{1}, \mathrm{PM}_{2.5}, \mathrm{PM}_{10}$ and TSP fractions (measured continuously and in terms of mass).

\section{Materials and methods}

\subsection{Sites description}

A pre-inspection to the studied nursery schools and rooms (through observations and interviews with the staff) was developed to capture relevant information on activities, building characteristics and potential sources of pollution.

This study was carried out in three rural nursery schools (RUR1, RUR2 and RUR3) located in Bragança district without significant influence of traffic emissions, and in an urban nursery school (URB1) located in Porto city (influenced by traffic emissions).

These four nursery schools have different management models: i) RUR1 is a public preschool managed with public funds by the municipal authorities and the Ministry of Education; ii) RUR2 and RUR3 are managed by non-profit social solidarity institution, and with a mix of public and private funds; and iii) URB1 is a full private for-profit nursery school. 
The front of URB1 building is surrounded by a street with a high volume of traffic while RUR2 and RUR3 schools are surrounded by low volume traffic streets in residential areas. RUR1 is located near a forested area.

In RUR1 there were children aged from 3 to 6 years separated in three classrooms located on the ground floor. Although the building has an HVAC system and electric heaters, these were not used during the sampling period, thus dominated natural ventilation (DNV) was considered for all classrooms.

RUR2 nursery school cares for 3 to 6 year old children and has only one classroom with air conditioning, but this unit was not in use during the sampling period, thus DNV was also considered.

In RUR3 children were aged up to 3 years old divided in 2 classrooms. The centennial building where it is located was in the past a primary school, but after 2011 it was remodelled to become a nursery school preserving the basic structural characteristics while providing the necessary comfort and functionality. Like RUR2, RUR3 had an HVAC system and electric heaters that were also turned off during the sampling period and DNV was considered.

URB1 nursery school had children from 3 months to 6 years of age divided in 6 different classrooms located on three floors. During the sampling periods, air conditioning and dehumidifier were frequently used in classrooms $\mathrm{A}$ and $\mathrm{B}$, thus dominated forced ventilation (DFV) was considered in these cases. During the study period the younger children (3 months to 1 year) spent the entire school period inside the classroom including sleeping time and meals. All the studied nursery schools had a lunch room on the ground floor with a kitchen using gas stoves with exception of RUR3 where the meals were previously prepared in RUR2. It was also observed that in RUR1 preschool children had lunch together with the primary school students. 
152 The general clean-up on the rural nursery schools was done by the school staff, while in the 153 urban school was carried out by an external company. All schools' clean-up was done before 154 the rest periods and at the end of the lunch time in the classrooms where children did not eat in 155 the lunch room.

156 Measurements were performed in 2 classrooms in RUR1 and RUR3, 1 classroom in RUR2 and 1573 classrooms in URB1, as well as in the lunch rooms of all nursery schools. Table 1 summarizes 158 the main characteristics for IAQ in each considered microenvironment. 
Table 1 - Summary of the main characteristics of each studied microenvironment and sampling periods.

\begin{tabular}{|c|c|c|c|c|c|c|c|c|c|}
\hline Nursery & Room & Type of use & $\begin{array}{l}\text { Children's } \\
\text { age (years) }\end{array}$ & Floor & $\begin{array}{c}\text { Area } \\
\left(\mathbf{m}^{2}\right)\end{array}$ & $\begin{array}{c}\text { Occupation } \\
\text { (Children + staff) }\end{array}$ & $\begin{array}{c}\text { Period of } \\
\text { occupation }\end{array}$ & Ventilation & $\begin{array}{c}\text { Sampling time } \\
\text { (weekdays + } \\
\text { weekend days) }\end{array}$ \\
\hline \multirow{3}{*}{ RUR1 } & A & Classroom & $4-5$ & Ground floor & 63 & $\begin{array}{l}\mathrm{FO}^{\mathrm{a}}: 25+2 \\
\mathrm{PO}^{\mathrm{b}}: 6+2\end{array}$ & $\begin{array}{c}09 \mathrm{~h}-12 \mathrm{~h} \\
14 \mathrm{~h}-15 \mathrm{~h} 30\end{array}$ & $\mathrm{DNV}^{\mathrm{c}}$ & $2+2$ \\
\hline & B & Classroom & 5 & Ground floor & 48 & $20+2$ & $\begin{array}{c}09 h-12 h \\
14 h-15 h 30\end{array}$ & DNV & $3+2$ \\
\hline & LR & Lunch room & $3-5$ & $\begin{array}{l}\text { Ground floor } \\
\text { (back) }\end{array}$ & 56 & $\begin{array}{c}\text { FO }: \sim 200 \\
\text { PO }: \sim 21\end{array}$ & $12 \mathrm{~h}-14 \mathrm{~h}$ & DNV & $1+0$ \\
\hline \multirow{2}{*}{ RUR2 } & A & Classroom & $3-6$ & $\begin{array}{l}\text { Ground floor } \\
\text { (back) }\end{array}$ & 32.5 & $14+2$ & $\begin{array}{l}09 \mathrm{~h}-11 \mathrm{~h} 30 \\
12 \mathrm{~h} 15-16 \mathrm{~h}\end{array}$ & DNV & $4+2$ \\
\hline & LR & Lunch room & $3-6$ & Ground floor & 26 & $14+2$ & $11 \mathrm{~h} 30-12 \mathrm{~h} 15$ & DNV & $3+0$ \\
\hline \multirow{3}{*}{ RUR3 } & A & Classroom & $<1-2$ & Ground floor & 23.5 & $23+2$ & $\begin{array}{c}08 \mathrm{~h}-11 \mathrm{~h} 30 \\
13 \mathrm{~h} 30-18 \mathrm{~h} \\
12 \mathrm{~h} 30-15 \mathrm{~h} 30 \\
\text { (sleeping time) }\end{array}$ & DNV & $4+2$ \\
\hline & B & Classroom & $2-3$ & Ground floor & 37.5 & 1 (Functioned as support room) & $\begin{array}{c}8 \mathrm{~h}-11 \mathrm{~h} 30 \\
12 \mathrm{~h} 30-18 \mathrm{~h}\end{array}$ & DNV & $3+0$ \\
\hline & LR & Lunch room & $<1-3$ & $\begin{array}{l}\text { Ground floor } \\
\text { (back) }\end{array}$ & 104 & 24 & $11 \mathrm{~h} 30-12 \mathrm{~h} 30$ & DNV & $3+0$ \\
\hline \multirow{4}{*}{ URB1 } & A & Classroom & $<2$ & $\begin{array}{l}\text { 1st floor } \\
\text { (back) }\end{array}$ & 38 & $23+2$ & $\begin{array}{c}07 \mathrm{~h} 30-19 \mathrm{~h} 30 \\
12 \mathrm{~h}-13 \mathrm{~h} \\
\text { (sleeping time) }\end{array}$ & DFV $^{d}$ & $4+2$ \\
\hline & B & Classroom & $2-3$ & $\begin{array}{l}\text { 1st floor } \\
\text { (back) }\end{array}$ & 21 & $23+2$ & $\begin{array}{c}08 \mathrm{~h} 30-10 \mathrm{~h} 50 \\
11 \mathrm{~h} 45-18 \mathrm{~h} 30 \\
12 \mathrm{~h}-15 \mathrm{~h} \\
\text { (sleeping time) }\end{array}$ & DFV & $4+0$ \\
\hline & $\mathrm{C}$ & Classroom & 4 & $\begin{array}{l}\text { 2nd floor } \\
\text { (front) }\end{array}$ & 59 & $29+2$ & $\begin{array}{c}09 \mathrm{~h}-11 \mathrm{~h} 30 \\
14 \mathrm{~h}-18 \mathrm{~h}\end{array}$ & DNV & $3+2$ \\
\hline & LR & Lunch room & $2-5$ & $\begin{array}{l}\text { Ground floor } \\
\text { (back) }\end{array}$ & 38 & 21 to 74 & $11 \mathrm{~h} 30-13 \mathrm{~h} 30$ & DNV & $3+0$ \\
\hline
\end{tabular}


Indoor concentrations of PM different fractions ( $\mathrm{PM}_{1}, \mathrm{PM}_{2.5}, \mathrm{PM}_{10}$ and TSP) were continuously measured using a TSI DustTrak ${ }^{\mathrm{TM}}$ DRX 8534 Aerosol Monitor (TSI, USA), using lightscattering laser method and previously calibrated by the manufacturer. The minimum and maximum limit detections are $0.001 \mathrm{mg} \mathrm{m}^{-3}$ and $150 \mathrm{mg} \mathrm{m}^{-3}$, respectively. The equipment was submitted to a standard zero calibration (available in the equipment) and data were validated prior to each measurement in the different rooms. Inside the rooms, the equipment was placed as close to the middle as possible, far from the windows, doors and room's corners, approximately at the same height of the breathing zone of the children. Indoor measurements were performed for at least 24 consecutive hours in each microenvironment, and, in some cases, both during weekdays (during occupancy and non-occupancy) and weekends, between April and June 2014. Hourly averages were calculated from a set of four measurements per hour (every 15 minutes) during the measurement periods. In RUR1 measurements were also made both in full occupation (FO) and partial occupation (PO) for one of the classrooms and for the lunch room (Table 1). The PO period corresponded to the week before the school Easter holidays.

The indoor hourly mean concentrations were compared with reference standards and guidelines to obtain the exceedances. Comparisons were performed with national and international reference values, namely: i) Portuguese legislation for $\mathrm{PM}_{10}\left(50 \mu \mathrm{g} \mathrm{m}^{-3}\right.$, plus $100 \%$ margin of tolerance (MT) if no mechanical ventilation system was working in the room) and $\mathrm{PM}_{2.5}(25 \mu \mathrm{g}$ $\mathrm{m}^{-3}$, plus $100 \%$ MT if no mechanical ventilation system was working in the room) (Portaria $\mathrm{n}^{\circ}$ 353-A/2013); and ii) WHO guidelines for $\mathrm{PM}_{10}\left(50 \mu \mathrm{g} \mathrm{m}^{-3}\right)$ and $\mathrm{PM}_{2.5}\left(25 \mu \mathrm{g} \mathrm{m}^{-3}\right)$ (WHO, 2010). These comparisons were performed considering 8-hour running means that were calculated per day of measurement for the Portuguese legislation and hourly means for WHO guidelines. 
Hourly $\mathrm{PM}_{2.5}$ and $\mathrm{PM}_{10}$ outdoor concentrations were obtained to calculate indoor/outdoor (I/O) ratios. Data was obtained for rural nursery schools, in the subsequent days after indoor measurements and with the same equipment used indoors, and for the urban nursery school from the nearest air quality station from the Air Quality Monitoring Network of the Porto Metropolitan Area, managed by the Regional Commission of Coordination and Development of Northern Portugal (Comissão de Coordenação e Desenvolvimento Regional do Norte) and under the responsibility of the Ministry of Environment. This station is classified as urban traffic and it is representative of the urban area studied (Mesquita, 2007).

\section{Results and Discussion}

\subsection{PM concentrations}

No significant differences were observed on PM concentrations between different weekdays; as the daily patterns during the different sampling weekdays in each room were very similar, the mean daily profiles for weekdays were considered to represent an average IAQ scenario. The same was considered for weekends.

Fig. 1 shows the mean daily profiles of $\mathrm{PM}_{1}, \mathrm{PM}_{2.5}, \mathrm{PM}_{10}$ and TSP (a) to d), respectively), for RUR1. Figs. 2-4 show the same for RUR2, RUR3 and URB1, respectively. Table 2 summarizes the basic statistical parameters (minimum, maximum, mean and median) of the hourly means for each microenvironment for the four nursery schools. 


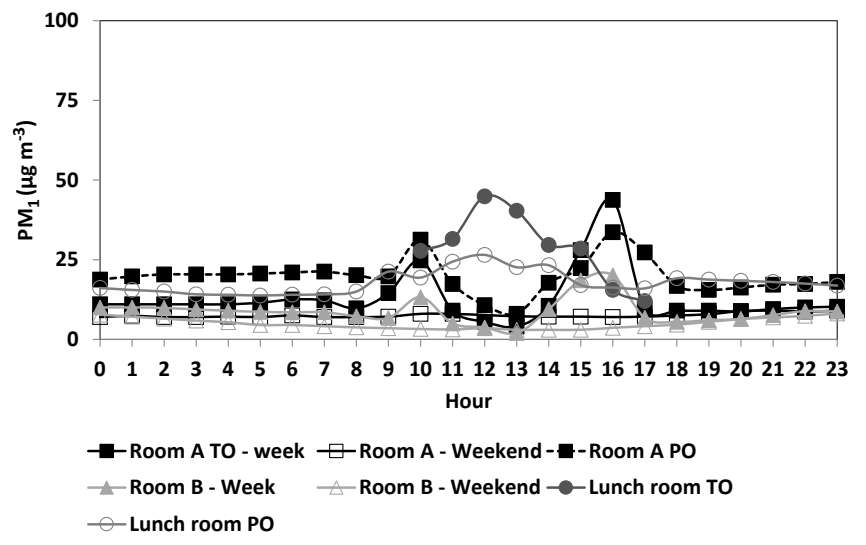

(a)

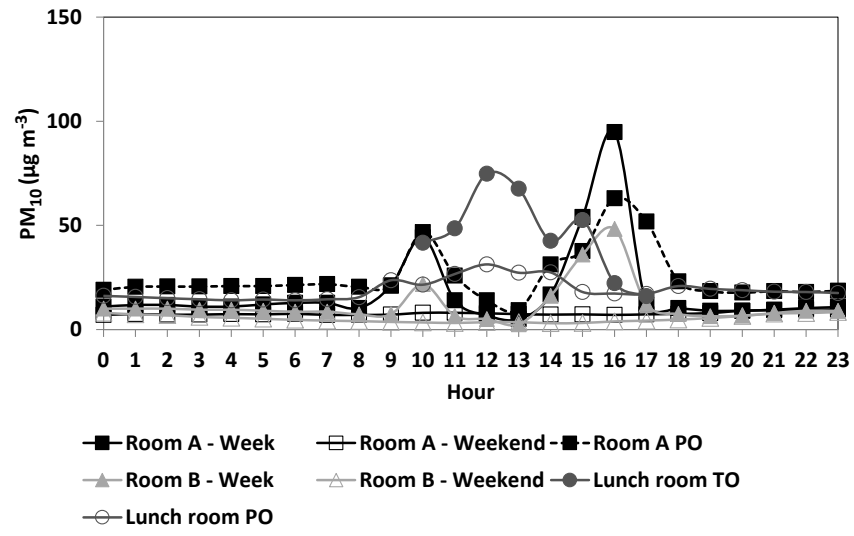

(c)

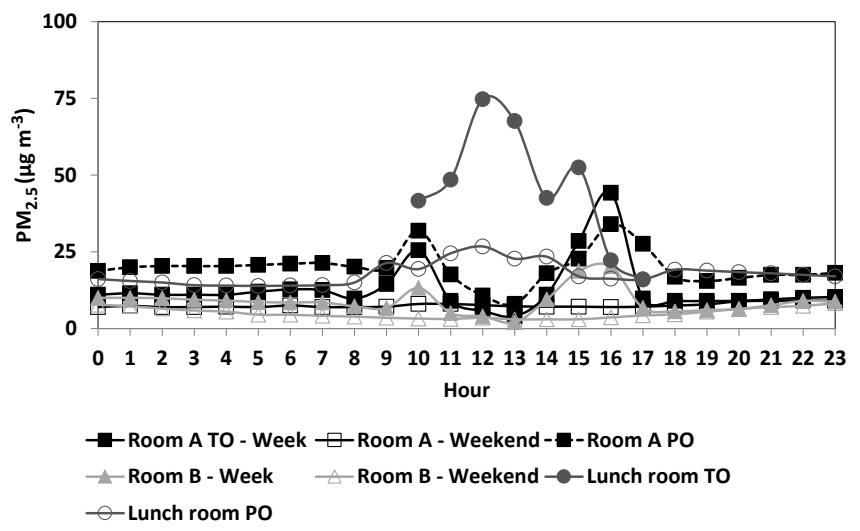

(b)

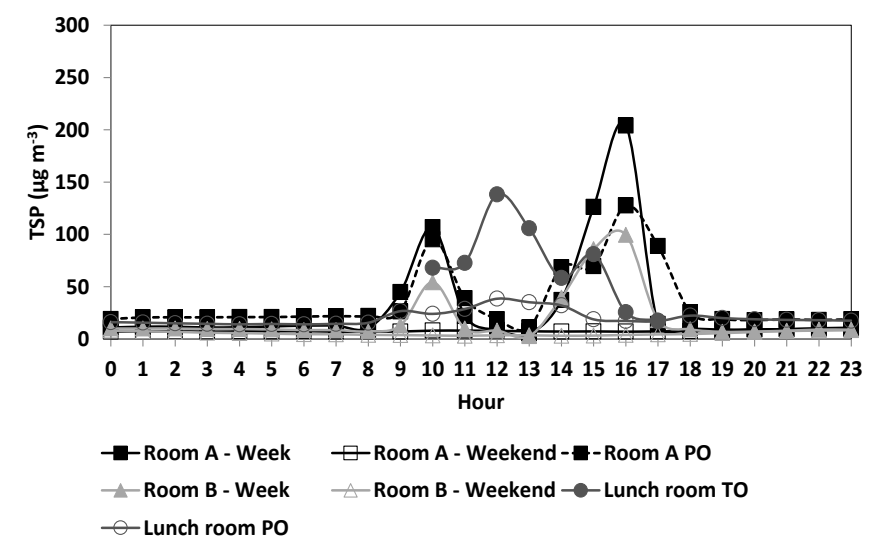

(d)

205 Figure 1. Mean PM concentrations for RUR1: a) $\mathrm{PM}_{1}$, b) $\mathrm{PM}_{2.5}$, c) $\mathrm{PM}_{10}$ and d) TSP. 


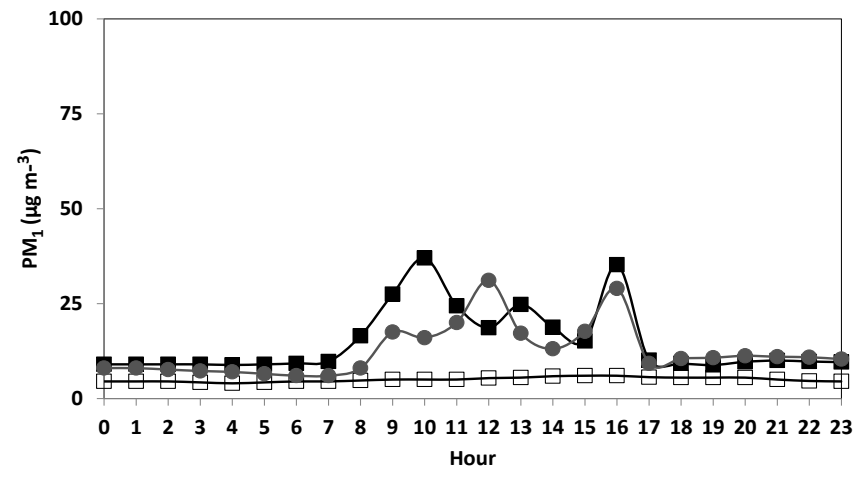

$\rightarrow$-Room A - Week $\square$ Room A - Weekend $\rightarrow$-Lunch room

(a)

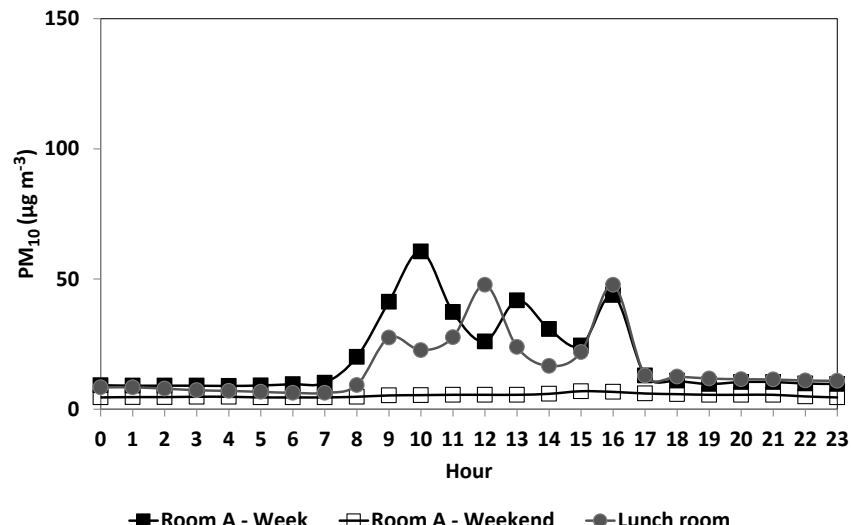

(c)

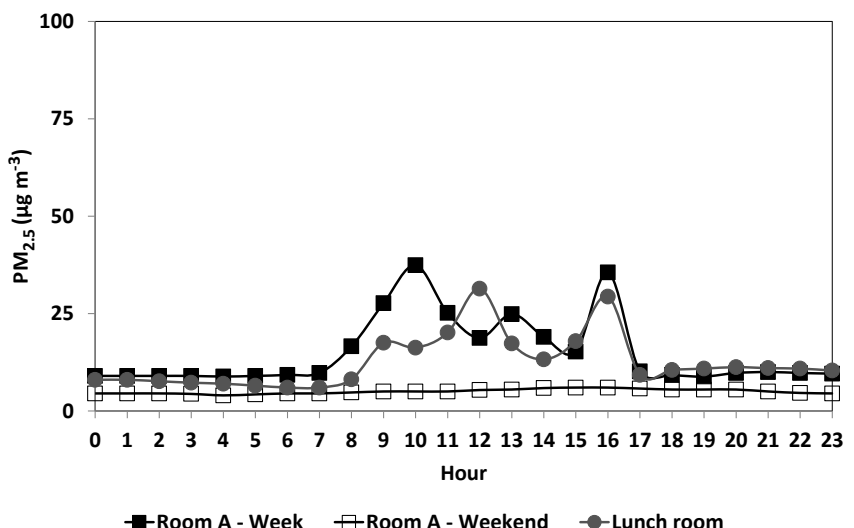

(b)

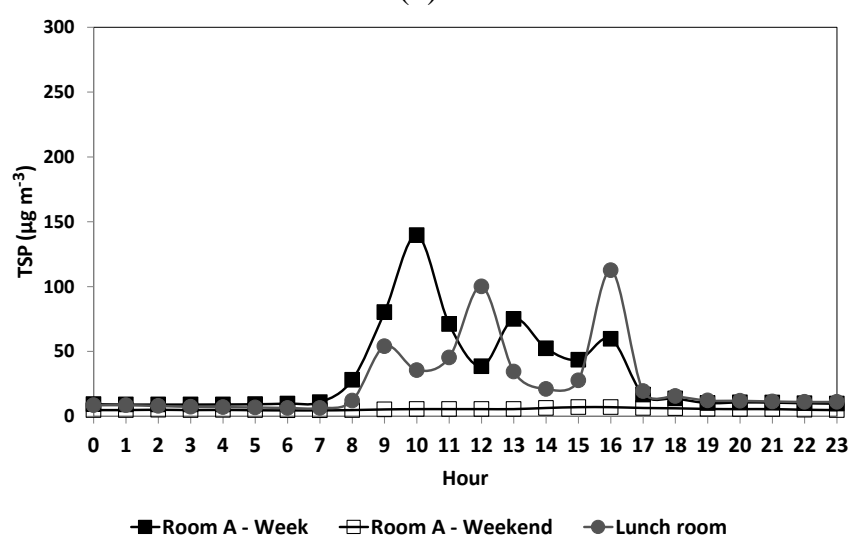

(d)

208 Figure 2. Mean PM concentrations for RUR2: a) $\mathrm{PM}_{1}$, b) $\mathrm{PM}_{2.5}$, c) $\mathrm{PM}_{10}$ and d) TSP. 


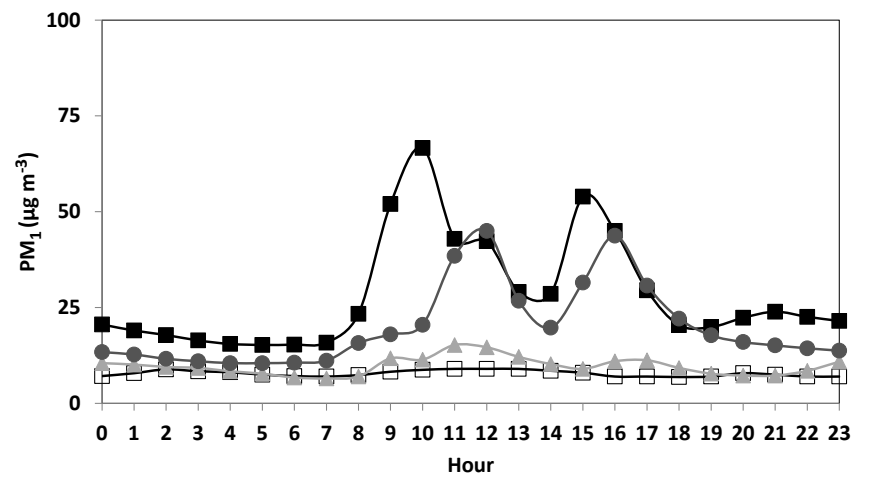

$\rightarrow$ Room A - Week $\square$ Room A - Weekend - Room B - Week - - Lunch room

(a)

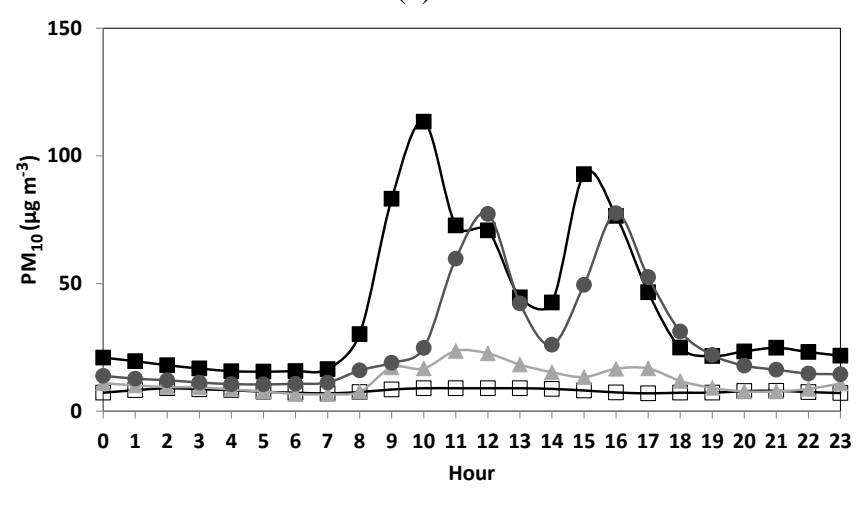

(c)

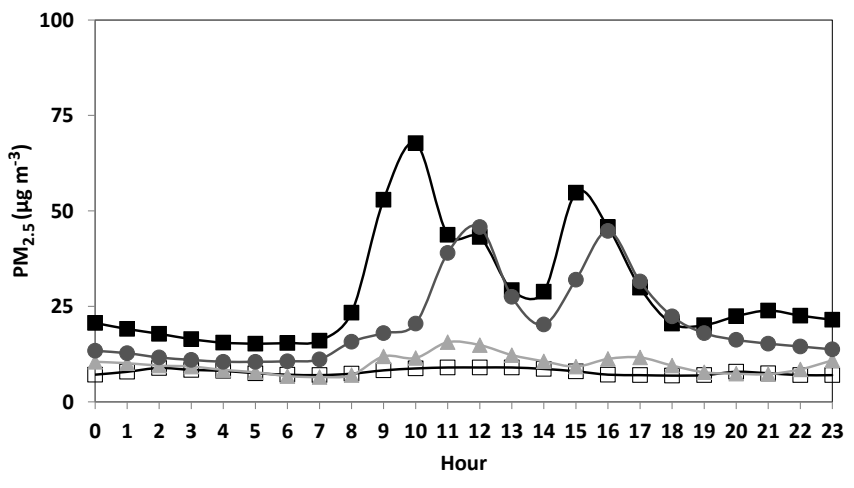

$\rightarrow$ Room A - Week $\square$ Room A - Weekend - -Room B - Week - - Lunch room (b)

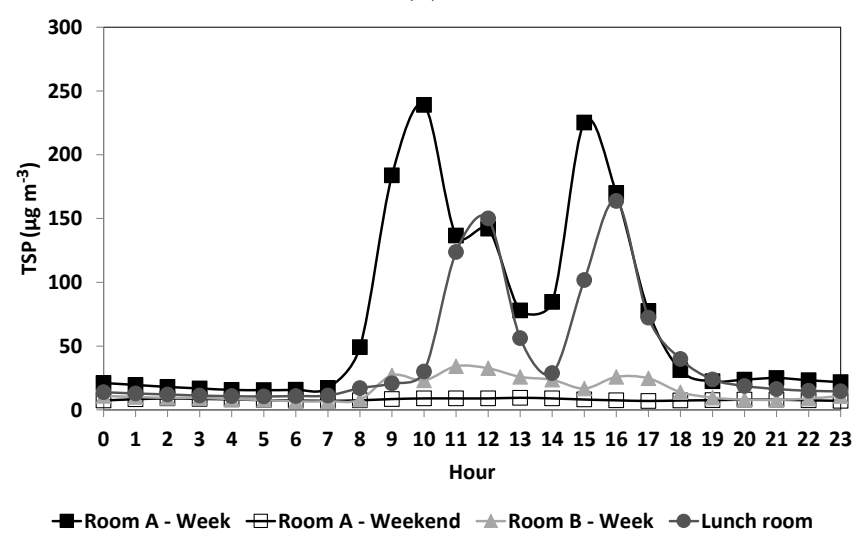

(d)

211 Figure 3. Mean PM concentrations for RUR3: a) $\mathrm{PM}_{1}$, b) $\mathrm{PM}_{2.5}$, c) $\mathrm{PM}_{10}$ and d) TSP. 


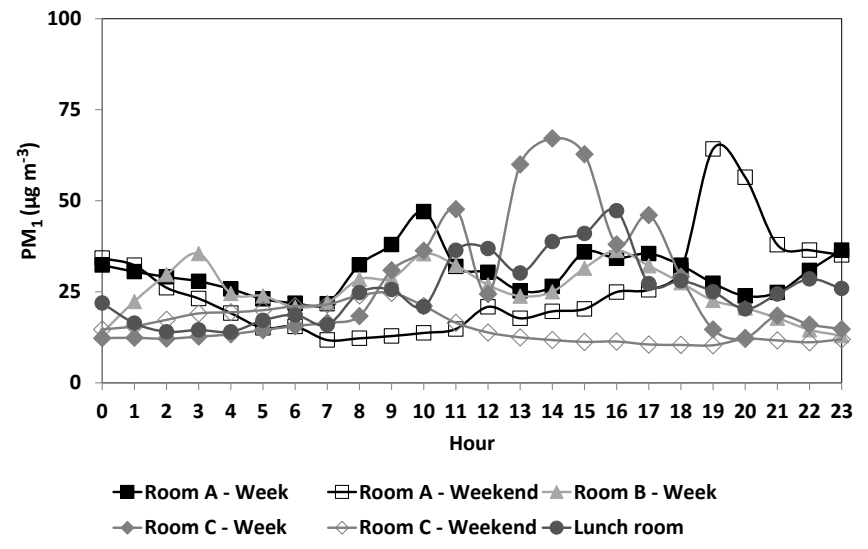

(a)

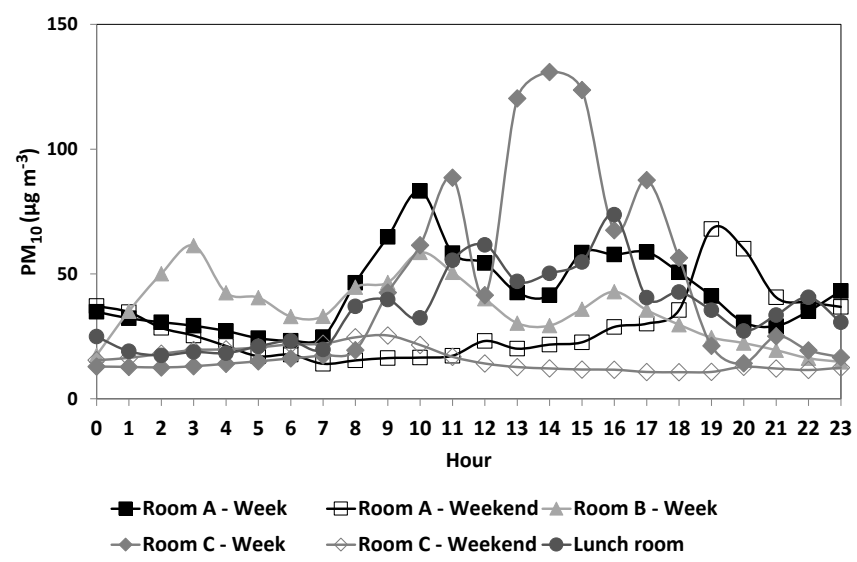

(c)

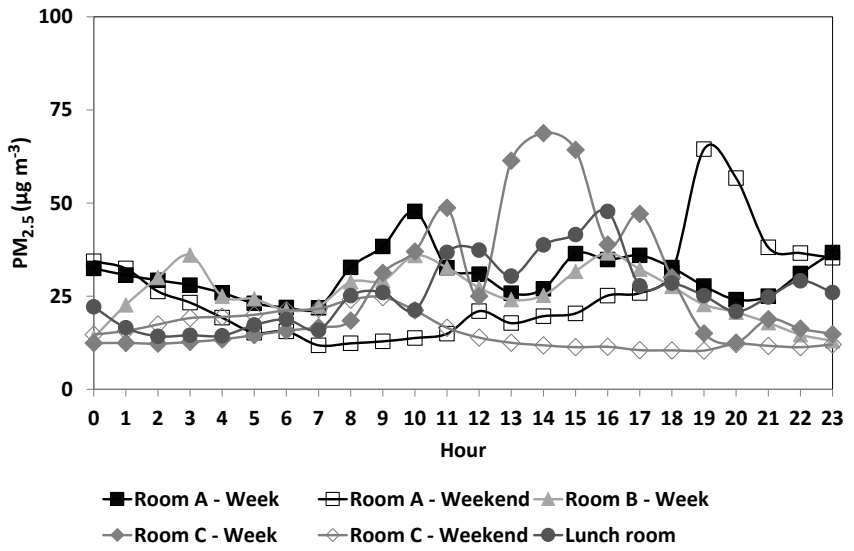

(b)

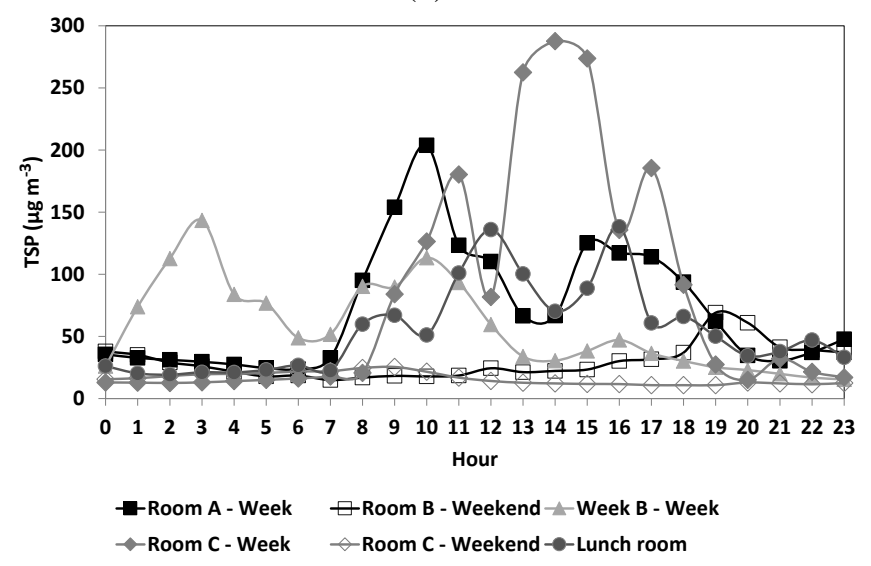

(d)

214 Figure 4. Mean PM concentrations for URB1: a) $\mathrm{PM}_{1}$, b) $\mathrm{PM}_{2.5}$, c) $\mathrm{PM}_{10}$ and d) TSP. 
Table 2 - Statistical parameters of the hourly mean data for each room studied at all nursery schools.

\begin{tabular}{|c|c|c|c|c|c|c|c|c|c|c|c|c|c|c|c|}
\hline & \multirow{2}{*}{$\begin{array}{c}\text { Nursery } \\
\text { Room }\end{array}$} & \multirow[b]{2}{*}{$\mathbf{A F o}^{a}$} & \multicolumn{4}{|c|}{ RUR1 } & \multicolumn{2}{|c|}{ RUR2 } & \multicolumn{3}{|c|}{ RUR3 } & \multicolumn{4}{|c|}{ URB1 } \\
\hline & & & $\mathbf{A}_{\mathbf{P O}}{ }^{\mathbf{b}}$ & B & $\mathrm{LR}_{\mathrm{FO}}{ }^{\mathrm{c}}$ & LRPO $^{d}$ & $\mathbf{A}$ & $\mathbf{L R}^{\mathrm{e}}$ & A & B & LR & $\mathbf{A}$ & B & $\mathrm{C}$ & LR \\
\hline \multirow{4}{*}{$\mathrm{PM}_{1}\left(\mu \mathrm{g} \mathrm{m}^{-3}\right)$} & Min & 4.00 & 8.00 & 2.00 & 12.00 & 12.50 & 5.00 & 5.00 & 8.00 & 6.00 & 7.00 & 12.47 & 7.15 & 10.00 & 8.50 \\
\hline & Max & 43.75 & 52.00 & 24.25 & 52.75 & 37.00 & 83.00 & 43.67 & 101.75 & 18.75 & 45.00 & 54.42 & 55.23 & 80.41 & 47.25 \\
\hline & Mean & 12.79 & 20.16 & 8.99 & 31.00 & 17.88 & 14.65 & 13.06 & 27.78 & 9.80 & 17.67 & 29.82 & 25.41 & 27.52 & 24.37 \\
\hline & Median & 10.75 & 17.75 & 8.00 & 27.88 & 16.00 & 12.25 & 10.63 & 22.00 & 9.00 & 15.00 & 29.47 & 25.92 & 18.46 & 23.13 \\
\hline \multirow{4}{*}{$\mathrm{PM}_{2.5}\left(\mu \mathrm{g} \mathrm{m}^{-3}\right)$} & Min & 4.00 & 8.00 & 2.00 & 12.00 & 12.50 & 5.00 & 5.00 & 8.25 & 6.00 & 7.00 & 12.60 & 7.22 & 10.00 & 8.75 \\
\hline & Max & 44.25 & 52.75 & 24.75 & 54.00 & 37.25 & 83.50 & 44.00 & 103.50 & 19.00 & 45.75 & 55.25 & 56.10 & 82.22 & 47.75 \\
\hline & Mean & 12.98 & 20.32 & 9.03 & 31.72 & 17.93 & 14.76 & 13.14 & 28.06 & 9.91 & 17.85 & 30.14 & 25.70 & 28.05 & 24.67 \\
\hline & Median & 11.00 & 18.00 & 8.00 & 28.63 & 16.00 & 12.25 & 10.75 & 22.25 & 9.00 & 15.00 & 29.98 & 26.07 & 18.51 & 23.25 \\
\hline \multirow{4}{*}{$\mathrm{PM}_{10}\left(\mu \mathrm{g} \mathrm{m}^{-3}\right)$} & Min & 5.00 & 9.25 & 2.50 & 16.00 & 13.00 & 5.00 & 5.50 & 9.00 & 6.00 & 7.00 & 13.87 & 9.73 & 10.13 & 14.50 \\
\hline & $\operatorname{Max}$ & 94.75 & 108.75 & 52.75 & 108.25 & 41.25 & 92.50 & 63.33 & 177.00 & 31.75 & 77.50 & 97.60 & 99.53 & 154.11 & 73.75 \\
\hline & Mean & 17.98 & 25.51 & 12.09 & 58.28 & 19.12 & 19.08 & 16.91 & 38.62 & 12.43 & 22.74 & 40.99 & 35.76 & 45.00 & 34.32 \\
\hline & Median & 11.38 & 19.50 & 8.88 & 55.50 & 16.50 & 13.00 & 11.00 & 29.25 & 10.00 & 15.75 & 40.30 & 33.17 & 21.83 & 32.63 \\
\hline \multirow{4}{*}{$\operatorname{TSP}\left(\mu \mathrm{g} \mathrm{m}^{-3}\right)$} & Min & 5.33 & 11.00 & 2.75 & 17.50 & 13.00 & 5.00 & 5.50 & 9.00 & 6.25 & 7.00 & 14.30 & 10.85 & 10.13 & 17.75 \\
\hline & Max & 204.00 & 234.50 & 113.50 & 229.00 & 47.25 & 169.75 & 131.00 & 388.75 & 48.00 & 163.75 & 240.98 & 245.38 & 319.08 & 138.25 \\
\hline & Mean & 30.52 & 35.60 & 19.30 & 101.75 & 20.45 & 29.75 & 26.33 & 67.32 & 15.85 & 31.79 & 66.28 & 57.96 & 84.41 & 51.94 \\
\hline & Median & 11.50 & 21.00 & 10.25 & 93.75 & 17.00 & 13.50 & 11.88 & 35.50 & 11.13 & 15.88 & 48.12 & 35.85 & 27.41 & 40.88 \\
\hline
\end{tabular}

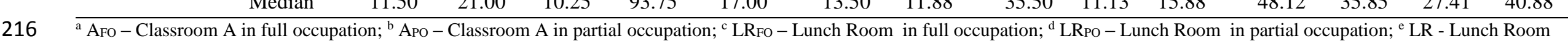


According to Figs. 1-4, it was possible to identify for all size fractions a typical profile for the PM concentration evolution at the classrooms of all nursery schools: the concentrations increased at the beginning of the morning (between $7 \mathrm{~h}$ and $9 \mathrm{~h}$ ), and decreased at the lunch hour (11h to $13 \mathrm{~h}$ ) when most of the children went to the lunch room. After the lunch period PM concentrations rose again until the school closed. The concentrations decreased sharply during the evening and midnight hours. In the lunch rooms the concentrations increased during the lunch period. The lowest concentrations were registered during the non-occupation periods (evening and midnight hours).

During weekends the profiles were generally constant for all the fractions, with the exception of Classroom A in URB1 (Fig. 4 a) to d)) in which there was a peak from $18 \mathrm{~h}$ to $21 \mathrm{~h}$ due to an open window during the measurement period allowing the entrance of outdoor PM probably from traffic emissions.

In RUR1 the highest concentrations from all size fractions were verified in the lunch room during FO, probably due to an elevated re-suspension caused by the occupants' movements (Fig. 1). Besides transported by children (on shoes and clothes) particles from outside could have contributed to the indoor concentrations. Classroom A registered higher PM concentrations than Classroom B, because the first was occupied by older children that had greater mobility and a higher level of activity which significantly contributed to the resuspension of particles. Branco et al. (2014a) reached the same conclusion. However, Classroom $\mathrm{A}$ in $\mathrm{PO}$ registered higher concentrations than in FO (the most common in Portuguese nursery schools). Thus, it seems that a low number of children in the classroom is enough to increase PM concentrations, which might be due to the children's activities. For the finer fractions $\left(\mathrm{PM}_{1}\right.$ and $\left.\mathrm{PM}_{2.5}\right)$ differences between the concentrations in $\mathrm{PO}$ and $\mathrm{FO}$ were more pronounced when compared with the differences registered for the coarser fractions $\left(\mathrm{PM}_{10}\right.$ and TSP) (Fig. 1), which lead to conclude that children's activities inside classrooms mainly 
contributed to decrease IAQ by increasing PM concentrations (namely finer fractions) to more dangerous levels to children's health.

In RUR2, RUR3 and URB1 the concentration peaks in classrooms and lunch rooms matched not only the occupation periods in which the children's activities caused particles re-suspension, but also the cleaning activities (late afternoon in classrooms and before meals in lunch rooms). In RUR3 the average concentrations registered in the classroom and lunch room during occupation periods were similar, once the doors, permanently open to the inner corridors, made these two spaces to work virtually as a single space (Fig. 3). In URB1 an increase of concentrations was detected in Classroom B during a non-occupation period (00h to 03h), which was probably due to an open window during the measurement period and meteorological factors that led to the entrance of particles from vegetation near this room (Fig. 4).

On average, URB1 registered PM concentrations higher than rural nursery schools, probably due to the higher traffic around this site (Table 2). Tong and Lam (1998), Fromme et al. (2005) and Yoon et al. (2011) also reported higher PM concentrations in urban nursery schools than in rural ones.

The concentrations reported from research in Asian countries (Zuraimi and Tham, 2008; Yang et al., 2009; Yoon et al., 2011) were in general considerably higher than those found in this study. Zuraimi and Tham (2008) and Yang et al. (2009) reported, respectively, $\mathrm{PM}_{2.5}$ and $\mathrm{PM}_{10}$ mean concentrations of $69.5 \mu \mathrm{g} \mathrm{m}^{-3}$ and $106.67 \mu \mathrm{g} \mathrm{m}^{-3}$ higher than those measured at all sites here reported. Yoon et al. (2011) reported TSP mean concentrations $\left(71.01 \mu \mathrm{g} \mathrm{m}^{-3}\right)$ similar to those observed in URB1, although they studied rural nursery schools and the concentrations obtained $\left(52.12 \mu \mathrm{g} \mathrm{m}^{-3}\right)$ were higher than those found in all rural nursery schools here studied. The concentrations recorded in the present study were, in general, similar to those reported in other European studies (Fromme et al., 2005; Wichmann et al., 2010; Branco et al., 2014a). 
266 Wichmann et al. (2010) reported mean values of $\mathrm{PM}_{2.5}\left(8.4 \mu \mathrm{g} \mathrm{m}^{-3}\right)$ similar to concentrations 267 observed in Classroom B of RUR1 and in Classroom B of RUR3, although their measurements were performed in an urban context. Branco et al. (2014a) also studied the same PM fractions in urban nursery schools of Porto city and reported similar mean concentrations of $\mathrm{PM}_{1}$ (Classrooms: $25.85 \mu \mathrm{g} \mathrm{m}^{-3}$; Lunch rooms: $30.40 \mu \mathrm{g} \mathrm{m}^{-3}$ ), $\mathrm{PM}_{2.5}$ (Classrooms: $26.84 \mu \mathrm{g} \mathrm{m}^{-3}$; Lunch rooms: $31.71 \mu \mathrm{g} \mathrm{m}^{-3}$ ), $\mathrm{PM}_{10}$ (Classrooms: $33.37 \mu \mathrm{g} \mathrm{m}^{-3}$; Lunch rooms: $39.74 \mu \mathrm{g} \mathrm{m}^{-3}$ ), and TSP (Classrooms: $53.11 \mu \mathrm{g} \mathrm{m}^{-3}$; Lunch rooms: $60,40 \mu \mathrm{g} \mathrm{m}^{-3}$ ) to those recorded in URB1. Cano (2012) reported mean concentrations of $\mathrm{PM}_{10}$ much higher, both in Porto $\left(230 \mu \mathrm{g} \mathrm{m}^{-3}\right)$ and in Lisboa $\left(4505 \mu \mathrm{g} \mathrm{m}^{-3}\right)$ than those here studied. According to the variety of values reported, it can be concluded that PM concentrations not only depend on the environmental and social contexts, but also on children's activities and internal characteristics of the buildings.

\subsection{PM size distribution}

Three different ratios $\left(\mathrm{PM}_{1} / \mathrm{PM}_{2.5}, \mathrm{PM}_{2.5} / \mathrm{PM}_{10}\right.$; and $\left.\mathrm{PM}_{10} / \mathrm{TSP}\right)$ were calculated considering the hourly mean concentrations for three different conditions: i) weekday occupancy; ii) weekday non-occupancy; and iii) weekend (when applicable). Results are represented in Table 3. 
Table 3 - PM size distribution in each studied microenvironment: mean values according to occupancy patterns.

\begin{tabular}{|c|c|c|c|c|c|c|c|c|c|c|}
\hline \multirow{3}{*}{ Nursery } & \multirow{3}{*}{ Room } & \multicolumn{6}{|c|}{ Weekdays } & \multirow{2}{*}{\multicolumn{3}{|c|}{ Weekends }} \\
\hline & & \multicolumn{3}{|c|}{ During occupation } & \multicolumn{3}{|c|}{ During non-occupation } & & & \\
\hline & & $\mathbf{P M}_{1} / \mathbf{P M}_{2.5}$ & $\mathbf{P M}_{2.5} / \mathrm{PM}_{10}$ & $\mathbf{P M}_{10} / \mathrm{TSP}$ & $\mathbf{P M}_{1} / \mathbf{P M}_{2.5}$ & $\mathbf{P M}_{2.5} / \mathbf{P M}_{10}$ & $\mathbf{P M}_{10} / \mathrm{TSP}$ & $\mathbf{P M}_{1} / \mathbf{P M}_{2.5}$ & $\mathbf{P M}_{2.5} / \mathbf{P M}_{10}$ & $\mathbf{P M}_{10} / \mathrm{TSP}$ \\
\hline \multirow{3}{*}{ RUR1 } & $\mathbf{A}_{\mathrm{Fo}}{ }^{\mathrm{a}}$ & 0.98 & 0.63 & 0.52 & 0.99 & 0.96 & 0.98 & 1.00 & 0.99 & 1.00 \\
\hline & B & 0.99 & 0.66 & 0.51 & 1.00 & 0.93 & 0.95 & 0.99 & 0.96 & 0.99 \\
\hline & $\mathbf{L R}_{\mathbf{F O}}{ }^{b}$ & 0.99 & 0.64 & 0.64 & - & - & - & - & - & - \\
\hline \multirow{2}{*}{ RUR2 } & $\mathbf{A}$ & 0.99 & 0.66 & 0.56 & 1.00 & 0.93 & 0.93 & 1.00 & 0.96 & 0.98 \\
\hline & $\mathbf{L R}^{\mathrm{c}}$ & 0.99 & 0.66 & 0.48 & 1.00 & 0.87 & 0.85 & - & - & - \\
\hline \multirow{2}{*}{ RUR3 } & $\mathbf{A}$ & 0.99 & 0.66 & 0.54 & 1.00 & 0.95 & 0.96 & 1.00 & 0.98 & 0.99 \\
\hline & B & 0.98 & 0.72 & 0.73 & 1.00 & 0.95 & 0.97 & - & - & - \\
\hline \multirow{4}{*}{ URB1 } & $\mathbf{A}$ & 0.99 & 0.64 & 0.54 & 0.99 & 0.91 & 0.96 & 0.99 & 0.89 & 0.96 \\
\hline & B & 0.99 & 0.79 & 0.80 & 0.99 & 0.72 & 0.68 & - & - & - \\
\hline & $\mathbf{C}$ & 0.98 & 0.57 & 0.50 & 0.99 & 0.87 & 0.89 & 0.99 & 0.97 & 1.00 \\
\hline & LR & 0.99 & 0.64 & 0.49 & 0.99 & 0.76 & 0.78 & - & - & - \\
\hline
\end{tabular}


For all conditions and microenvironments $\mathrm{PM}_{1} / \mathrm{PM}_{2.5}$ ratio was close to 1 , meaning that the majority of $\mathrm{PM}_{2.5}$ was due to particles with less than $1 \mu \mathrm{m}$ diameter. Alves et al. (2015) that conducted an air quality monitoring campaign in a secondary school of the municipality of Anadia (Portugal) reported the same for all measured spaces. On weekends and non-occupancy periods, $\mathrm{PM}$ concentrations were mainly due to the finer fractions, with $\mathrm{PM}_{2.5} / \mathrm{PM}_{10}$ ratio close to 1 , in contrast with the occupancy periods $\left(\mathrm{PM}_{2.5} / \mathrm{PM}_{10}\right.$ mean ratio of about 0.60 , and $\mathrm{PM}_{10}$ /TSP mean ratio of about 0.56 ), showing the contribution of coarser particles in those periods. These results are consistent with findings made for Alves et al. (2015) that reported lower $\mathrm{PM}_{2.5} / \mathrm{PM}_{10}$ ratios for occupancy periods than in "day + night" periods (day + night refers to the entire monitoring campaign, comprising occupancy and vacant periods). Therefore, it was possible to confirm the association between children's activities and PM concentrations: during occupation periods coarser particles re-suspended, settling during non-occupation periods when there were no movements inside the rooms._Alves et al. (2013) also pointed for an urban kindergarten in Aveiro, Portugal that the settling of coarser particles after school hours contributed to increased submicron particles $\mathrm{PM}_{1} / \mathrm{PM}_{2.5}$ ratios during the night.

The ratios calculated for RUR2 showed similar values in the classroom and in the lunch room due to the permanently open doors to the inner corridors of these two microenvironments. In URB1 the $\mathrm{PM}_{2.5} / \mathrm{PM}_{10}$ and $\mathrm{PM}_{10} / \mathrm{TSP}$ ratios were lower in Classroom $\mathrm{C}$ (older children) than in A and B (younger children) showing that the level of children's activity (higher for older children) and their activities in general, boosted the re-suspension phenomenon, mainly of the coarser fractions. Alves et al. (2013) also reported, that human activity was seemingly the most important factor to account for the indoor levels of coarse particles. Thus, it is expected to find the highest concentrations of coarser PM fractions at the classrooms occupied by older children. However this conclusion can only be applied for nursery schools because for higher education levels students have lower activity levels (seated during the class periods). Alves et al. (2015) 
reported for computer classrooms in a secondary school, higher $\mathrm{PM}_{2.5} / \mathrm{PM}_{10}$ (0.74) and $310 \mathrm{PM}_{10} / \mathrm{TSP}(0.82)$ ratios than in Classroom $\mathrm{C}$ of URB1, which presupposes a lower re311 suspension phenomenon contribution in this case. Branco et al. (2014a) also reported for nursery schools that the highest PM concentrations were usually found at the classrooms

313 occupied by older children for all size fractions; however, for the study here reported this 314 behaviour was observed only for the coarser fractions, which was also verified by Alves et al. 315 (2013). The results seemed to indicate that the finer fractions $\left(\mathrm{PM}_{2.5}\right)$ probably depended more on internal features of the rooms than on children's activities.

317 Despite these results it must be considered that a wide range of $\mathrm{PM}_{1} / \mathrm{PM}_{2.5}$ and $\mathrm{PM}_{2.5} / \mathrm{PM}_{10}$ ratios has been reported worldwide for different schools, depending on season, meteorology, occupancy rates, physical characteristics of buildings, activities inside the classrooms and ventilation habits.

\subsection{Comparison with standards and guidelines}

322 Table 4 shows the exceedances (\%) to the standards and guidelines referred in Materials and methods section. 


\begin{tabular}{|c|c|c|c|c|c|c|c|c|c|c|c|c|c|}
\hline \multirow{3}{*}{ Nursery } & \multirow{3}{*}{ Room } & \multicolumn{6}{|c|}{ Weekdays } & \multicolumn{6}{|c|}{ Weekends } \\
\hline & & \multicolumn{2}{|c|}{ WHO [24h] } & \multicolumn{4}{|c|}{ Portuguese Legislation } & \multicolumn{2}{|c|}{ WHO [24h] } & \multicolumn{4}{|c|}{ Portuguese Legislation } \\
\hline & & $\mathbf{P M}_{2.5^{\mathrm{a}}}$ & $\mathbf{P M}_{10}{ }^{b}$ & $\mathbf{P M}_{2.5}{ }^{\mathbf{a}}$ & $\mathbf{P M}_{10}{ }^{\mathrm{b}}$ & $\mathrm{PM}_{2.5} \mathrm{MT}^{\mathrm{c}}$ & $\mathrm{PM}_{10} \mathrm{MT}^{\mathrm{d}}$ & $\mathbf{P M}_{2.5}$ & $\mathbf{P M}_{10}$ & $\mathbf{P M}_{2.5}$ & $\mathbf{P M}_{10}$ & $\mathbf{P M}_{2.5}$ MT & $\mathrm{PM}_{10} \mathrm{MT}$ \\
\hline \multirow{3}{*}{ RUR1 } & $\mathbf{A}_{\mathrm{Fo}}{ }^{\mathrm{e}}$ & $0 \%$ & $0 \%$ & $0 \%$ & $0 \%$ & $\mathrm{na}^{\mathrm{f}}$ & na & $0 \%$ & $0 \%$ & $0 \%$ & $0 \%$ & na & na \\
\hline & B & $50 \%$ & $0 \%$ & $100 \%$ & $0 \%$ & $0 \%$ & $0 \%$ & $0 \%$ & $0 \%$ & $0 \%$ & $0 \%$ & na & na \\
\hline & $\operatorname{LR}_{\mathrm{FO}}{ }^{\mathrm{g}}$ & $0 \%$ & $0 \%$ & $0 \%$ & $0 \%$ & na & na & $0 \%$ & $0 \%$ & $0 \%$ & $0 \%$ & na & na \\
\hline \multirow{2}{*}{ RUR2 } & $\mathbf{A}$ & $0 \%$ & $0 \%$ & $50 \%$ & $0 \%$ & na & na & na & na & na & na & na & na \\
\hline & $\mathbf{L R}^{\mathbf{h}}$ & $0 \%$ & $0 \%$ & $67 \%$ & $0 \%$ & na & na & $0 \%$ & $0 \%$ & $0 \%$ & $0 \%$ & na & na \\
\hline \multirow{2}{*}{ RUR3 } & $\mathbf{A}$ & $0 \%$ & $0 \%$ & $0 \%$ & $0 \%$ & na & na & na & na & na & na & na & na \\
\hline & B & $33 \%$ & $0 \%$ & $100 \%$ & $67 \%$ & $0 \%$ & $0 \%$ & $0 \%$ & $0 \%$ & $0 \%$ & $0 \%$ & na & na \\
\hline \multirow{4}{*}{ URB1 } & $\mathbf{A}$ & $0 \%$ & $0 \%$ & $0 \%$ & $0 \%$ & na & na & na & na & na & na & na & na \\
\hline & B & $0 \%$ & $0 \%$ & $100 \%$ & $100 \%$ & $0 \%$ & $0 \%$ & - & na & $\mathrm{Na}$ & na & na & na \\
\hline & $\mathbf{C}$ & $100 \%$ & $0 \%$ & $100 \%$ & $33 \%$ & na & na & $50 \%$ & $0 \%$ & $100 \%$ & $50 \%$ & na & na \\
\hline & LR & $100 \%$ & $0 \%$ & $67 \%$ & $67 \%$ & na & na & na & na & na & na & na & na \\
\hline
\end{tabular}


327 WHO guidelines for $\mathrm{PM}_{2.5}$ were exceeded in RUR1 (Classroom A in PO: 50\%), RUR3

328 (Classroom A: 33\%), and in all URB1 microenvironments where the highest exceedances were

329

330

331

332 found. In Classroom A of URB1 exceedances were recorded even on weekends (50\%). WHO guidelines for $\mathrm{PM}_{10}$ were only exceeded in URB1 (Classroom C: 33\%).

According to Portuguese legislation, $\mathrm{PM}_{2.5}$ and $\mathrm{PM}_{10}$ exceedances only occurred in URB1 (classrooms $\mathrm{A}$ and $\mathrm{B}$ and lunch room). The differences between exceedances to WHO guidelines and to Portuguese legislation in this particular case, may be the result from the nonapplication of the MT - in these sites there were mechanical ventilation systems operating during measurement periods (DFV). Classroom A even reported exceedances on weekends, which do not contribute to children's exposure, but allowed indicating that probably there were internal PM sources in this microenvironment. The study of PM composition may allow to better understand PM sources in this room.

In general, more exceedances, both to WHO guidelines and to Portuguese legislation, were found for the finer fraction $\left(\mathrm{PM}_{2.5}\right)$, which is more harmful to human health than the coarser $\left(\mathrm{PM}_{10}\right)$ fraction. Branco et al. (2014a) also reported more exceedances to WHO guidelines for the $\mathrm{PM}_{2.5}$ fraction. As far as known this is the only study beyond the present one that performed comparisons with national and international reference values for nursery schools. Therefore, and for a more complete analysis comparisons were made with values obtained for other types of schools. Alves et al. (2015) also reported more exceedances to the Portuguese legislation for $\mathrm{PM}_{2.5}$ fraction, and Rovelli et al. (2014) found in three primary and four secondary schools located in the urban area of Milan $\mathrm{PM}_{2.5}$ and $\mathrm{PM}_{10}$ 24-h mean concentrations above the guideline values established by WHO. Moreover, Sousa et al. (2012b) reviewed indoor $\mathrm{PM}_{10}$ and $\mathrm{PM}_{2.5}$ at nursery and primary schools and referred that PM concentrations sampled at the Asian countries largely exceeded WHO guidelines, although there were also found levels surpassing legislated limits and WHO guidelines in several European countries. 
In places where there were significant exceedances children may have a higher probability of developing lung diseases, asthma and other respiratory problems (WHO, 2010).

\subsection{Indoor/Outdoor ratios}

Indoor concentrations were compared with those outdoors using I/O ratios. Mean I/O ratios were obtained for each studied room in the four nursery schools and are presented in Table 5.

Table 5 - I/O ratios for $\mathrm{PM}_{2.5}$ and $\mathrm{PM}_{10}$ : mean values observed in each studied site for weekdays and weekends and respective minimum and maximum (min-max).

\begin{tabular}{|c|c|c|c|c|c|}
\hline \multirow{2}{*}{ Nursery } & \multirow{2}{*}{ Room } & \multicolumn{2}{|c|}{$\mathbf{P M}_{2.5}$} & \multicolumn{2}{|c|}{$\mathbf{P M}_{10}$} \\
\hline & & Weekday & Weekend & Weekday & Weekend \\
\hline \multirow{5}{*}{ RUR1 } & $\mathrm{A}_{\mathrm{FO}}{ }^{\mathrm{a}}$ & $1.03(0.24-5.47)$ & $0.64(0.39-0.95)$ & $1.23(0.24-9.17)$ & $0.55(0.30-0.80)$ \\
\hline & $\mathrm{A}_{\mathrm{PO}}{ }^{\mathrm{b}}$ & $1.49(0.47-4.21)$ & - & $1.62(0.44-6.10)$ & - \\
\hline & $\mathrm{B}$ & $0.69(0.12-2.51)$ & $0.43(0.19-0.81)$ & $0.81(0.12-4.67)$ & $0.37(0.16-0.69)$ \\
\hline & $\mathrm{LR}_{\mathrm{FO}}{ }^{\mathrm{c}}$ & $2.06(1.10-3.62)$ & - & $2.61(1.44-4.86)$ & - \\
\hline & $\mathrm{LR}_{\mathrm{PO}}{ }^{\mathrm{d}}$ & $1.27(0.68-2.10)$ & - & $1.11(0.61-1.72)$ & - \\
\hline \multirow{2}{*}{ RUR2 } & $\mathrm{A}$ & $1.06(0.47-4.40)$ & $0.43(0.26-0.61)$ & $1.13(0.42-4.24)$ & $0.38(0.22-0.57)$ \\
\hline & B & $0.93(0.29-3.63)$ & & $0.97(0.26-4.62)$ & - \\
\hline \multirow{3}{*}{ RUR3 } & $\mathrm{A}$ & $2.08(0.76-6.77)$ & $0.66(0.41-0.90)$ & $2.36(0.69-8.59)$ & $0.57(0.36-0.90)$ \\
\hline & $\mathrm{B}$ & $0.71(0.31-1.41)$ & - & $0.73(0.28-1.61)$ & - \\
\hline & $\mathrm{LR}^{\mathrm{e}}$ & $1.54(0.53-5.54)$ & - & $1.73(0.47-7.50)$ & - \\
\hline \multirow{4}{*}{ URB1 } & $\mathrm{A}$ & $12.21(0.93-44.67)$ & $6.64(0.49-28.40)$ & $2.99(0.99-22.84)$ & $1.38(0.43-6.31)$ \\
\hline & B & $12.33(1.98-37.90)$ & - & $6.22(0.62-63.57)$ & - \\
\hline & $\mathrm{C}$ & $7.39(1.43-27.41)$ & $5.83(1.36-25.28)$ & $6.19(0.39-70.88)$ & $2.04(0.45-13.83)$ \\
\hline & LR & $5.67(0.90-23.88)$ & - & $3.04(0.37-50.25)$ & - \\
\hline
\end{tabular}

$\overline{\mathrm{a}} \mathrm{A} \mathrm{FO}-$ Classroom A in full occupation; ${ }^{\mathrm{b}} \mathrm{APO}-$ Classroom A in partial occupation; ${ }^{\mathrm{c}} \mathrm{LR}$ FO - Lunch Room in full occupation; ${ }^{\mathrm{d}}$ LRPO - Lunch Room in partial occupation; ${ }^{\mathrm{e}} \mathrm{LR}$ - Lunch Room

In general, the I/O ratios were higher than 1 during weekdays in the rural nursery schools as well as in the urban one, which was probably associated with the activities and the re-suspension phenomenon. These results are consistent with the findings from Yoon et al. (2011) and Cano et al. (2012) in Korean and Portuguese nursery schools, respectively. As far as the authors knowledge goes there are only few studies in nursery schools which referred I/O ratios (Yang et al., 2009; Cano et al., 2012; Branco et al., 2014a), so comparisons were made with other types of schools environments. Parker et al. (2008) that performed a study in an elementary 
school in Salt Lake City (UT, USA) reported that indoor sources resulted in indoor coarse PM concentrations being higher than outdoors when the building was occupied, which is in agreement with the results obtained from this study, and reported by Almeida et al. (2011) and Jovanović et al. (2014) from Portuguese and Serbian primary schools, respectively. Specifically, Classroom B in RUR3 registered an I/O ratio of 0.71 which was expected since this room had little activity. In contrast, Guo et al. (2010) that studied $\mathrm{PM}_{2.5}$ concentrations in a school of Queensland Australia did not found a significant difference in I/O ratio between occupied and unoccupied conditions in the classrooms.

In URB1, classrooms A and B registered the highest $\mathrm{I} / \mathrm{O}$ ratios for $\mathrm{PM}_{2.5}$. Tippayawong et al. (2009) also reported for schools environments of Chiang Mai, Thailand higher I/O ratios for smaller fractions. However, in this case I/O ratios were less than 1. During the weekend periods, URB1 registered I/O ratios higher than 1 in all microenvironments, which suggested that the outdoor influence on PM indoor concentrations was not significant when compared with indoor sources, namely the re-suspension phenomena. However, in rural nursery schools the ratios obtained for all classrooms were lower than 1. Crist et al. (2008) reported for rural and urban primary schools in Ohio, USA I/O ratios lower than 1 in non-school days. Braniš and J. Šafranek (2011) also reported I/O ratios lower than 1 in weekends + holidays periods for school gyms in urban, periphery and suburban primary schools in Prague, Czech Republic. These results also suggest that occupation and ocupants activities can significantly increase the indoor PM concentrations. Yang et al. (2009), Goyal et al. (2009) and Ismail et al. (2010) that performed studies in a school building located near an urban roadway in Delhi City India and in primary schools of Terengganu Malaysia, respectivly, reported I/O ratio values for $\mathrm{PM}_{10}$ of 2.06, 2.45 and 2.60, respectively, similar to URB1. Branco et al. (2014a) reported higher I/O ratios, which were higher in the classrooms when compared to the lunch rooms. The same was 
verified in this study; however, the reported mean values both for weekdays and weekends (4.35 and 1.78, respectively) were slightly lower than those registered in URB1.

\section{Conclusions}

This study allowed to better understand the behaviour of $\mathrm{PM}_{1}, \mathrm{PM}_{2.5}, \mathrm{PM}_{10}$ and TSP concentrations in rural and urban nursery schools, with full, partial and without occupation, and the influence of environmental and social characteristics on the concentrations of nursery schools' microenvironments.

Mean PM concentrations for all fractions were higher in the urban nursery school than in the rural ones, which might have been related to outdoor traffic emissions. Despite this, results from I/O ratios allowed to conclude that the recorded concentrations depended more significantly on indoor sources.

According to WHO guidelines and Portuguese legislation, exceedances for $\mathrm{PM}_{2.5}$ and $\mathrm{PM}_{10}$ were found mainly in the urban nursery school. In the classrooms occupied by older children, higher PM concentrations of coarser fractions were observed, probably due to the re-suspension phenomenon, which was boosted by children's mobility. However, measurements during partial and full occupation periods demonstrated that a low number of children in the classroom was enough to increase PM concentrations (as shown by the higher concentrations in partial occupation periods than those in full occupation periods), which might be due to the children's activities. Cleaning and cooking activities as well as children mobility appeared to be the major causes of the reported concentrations in lunch rooms.

Considering the results achieved, it is recommended to implement simple measures aiming the mitigation of the non-compliances found, like the improvement of the air renovation (higher and efficient ventilation habits) and changes in cleaning activities' (more efficient techniques 
416 for removing dust), which would consequently improve children's and childcare workers'

417 overall life quality.

418 In the future it could be important to study nursery schools in suburban context as well as other

419 microenvironments, such as homes, to help supporting these findings and to study the 420 association of PM indoor air pollution with children's daily exposure. Determining PM 421 composition is also important to better understand the differences between distinct contexts and

422 to clearly identify sources of PM in indoor air.

423

\section{Acknowledgements}

425 The authors are grateful to the nursery schools involved in this study and to Comissão de 426 Coordenação e Desenvolvimento Regional do Norte (CCDR-N) for kindly providing the 427 outdoor air quality data. The authors are also grateful to Fundação para a Ciência e a 428 Tecnologia (FCT), COMPETE, QREN and EU for PTDC/SAU-SAP/121827/2010 funding. 429 PTBS Branco and SIV Sousa are also grateful to FCT, POPH/QREN and European Social Fund 430 (ESF) for the financial support of grants SFRH/BD/97104/2013 and SFRD/BPD/91918/2012, 431 respectively. 


\section{References}

Almeida, S. M., Canha, N., Silva, A., Freitas, M. C., Pegas, P., Alves, et al., 2011. Children exposure to atmospheric particles in indoor of Lisbon primary schools. Atmos. Environ. 45, 7594-7599.

Alves, C., Nunes, T., Silva, J., Duarte, M., 2013. Comfort Parameters and Particulate Matter $\left(\mathrm{PM}_{10}\right.$ and $\left.\mathrm{PM}_{2.5}\right)$ in School Classrooms and Outdoor. Air. Aerosol Air Qual. Res., 13, 15211535.

Alves, C., Duarte, M., Ferreira, M., Alves, A., Almeida, A., Cunha, Â., 2015. Air quality in a school with dampness and mould problems. Air Qual. Atmos. Health. 1-9.

Branco, P. T. B. S., Alvim-Ferraz, M. C. M., Martins, F. G., Sousa, S. I. V., 2014a. Indoor air quality in urban nurseries at Porto city: Particulate matter assessment. Atmos. Environ. 84, 133143.

Branco, P. T. B. S., Alvim-Ferraz, M. C. M., Martins, F. G., Sousa, S. I. V., 2014b. The microenvironmental modelling approach to assess children's exposure to air pollution - A review. Environ. Res. 135, 317-332.

Braniš, M., Šafránek, J., 2011. Characterization of coarse particulate matter in school gyms. Environ. Res. 111, 485-491.

Cano, M., Nogueira, S., Papoila, A. L., Aguiar, F., Martins, P., Marques, et al., Indoor Air Quality in Portuguese Children Day Care Centres - ENVIRH Project. Proceedings of the Second International Conference on Building Energy and Environment, pp. 414-421, 2012.

Crist, K. C., Liu, B., Kim, M., Deshpande, S. R., John, K., 2008. Characterization of fine particulate matter in Ohio: Indoor, outdoor, and personal exposures. Environ. Res. 106, 62-71. 
455

456

457

458

459

460

461

462

463

464

465

466

467

468

469

470

471

472

473

474

475

476

Darus, F. M., Nasir, R. A., Sumari, S. M., Ismail, Z. S., Omar, N. A., 2012. Heavy Metals

Composition of Indoor Dust in Nursery Schools Building. Procedia Soc. Behav. Sci. 38, 169175.

Decreto-Lei nº 118/2013. Ministério da Economia e do Emprego. Diário da República - I Série, $\mathrm{N}^{\circ} 159,4988-5005$.

Fonseca, J., Slezakova, K., Morais, S., Pereira, M. C., 2014. Assessment of ultrafine particles in Portuguese preschools: levels and exposure doses. Indoor Air. 24, 618-628.

Fromme, H., Lahrz, T., Hainsch, A., Oddoy, A., Piloty, M., Rüden, H., 2005. Elemental carbon and respirable particulate matter in the indoor air of apartments and nursery schools and ambient air in Berlin (Germany). Indoor Air. 15, 335-341.

Goyal, R., Khare, M., 2009. Indoor-outdoor concentrations of RSPM in classroom of a naturally ventilated school building near an urban traffic roadway. Atmos. Environ. 43, 60266038.

Guo, H., Morawska, L., He, C., Zhang, Y. L., Ayoko, G., Cao, M., 2010. Characterization of particle number concentrations and $\mathrm{PM}_{2.5}$ in a school: influence of outdoor air pollution on indoor air. Environ. Sci. Pollut. R. 17, 1268-1278.

Hagerhed-Engman, L., Borneha, C. G., Sundell, J., Aberg, N., 2006. Day-care attendance and increased risk for respiratory and allergic symptoms in preschool age. Allergy. 61, 789.

Ismail, M., Sofian, M., Zafirah, N., Abdullah, A. M. 2010 Indoor air quality in selected samples of primary schools in Kuala Terengganu, Malaysia. Environment Asia 3, 103-108.

Jovanović, M., Vučićević, B., Turanjanin, V., Živković, M., Spasojević, V., 2014. Investigation of indoor and outdoor air quality of the classrooms at a school in Serbia. Energy. 77, 42-48. 
Lu, X., Zhang, X., Li, L.Y., Chen, H., 2014. Assessment of metals pollution and health risk in dust from nursery schools in Xi'an, China. Environ. Res. 128, 27-34.

Parker, J. L., Larson, R. R., Eskelson, E., Wood, E. M., Veranth, J. M., 2008. Particle size distribution and composition in a mechanically ventilated school building during air pollution episodes. Indoor Air. 18, 386-393.

Pegas, P.N., Nunes, T., Alves, C.A., Silva, J.R., Vieira, S.L.A., Caseiro, A., et al., 2012. Indoor and outdoor characterisation of organic and inorganic compounds in city centre and suburban elementary schools of Aveiro, Portugal. Atmos. Environ. 55, 80-89.

Portaria n 353-A/2013. Ministérios do Ambiente, Ordenamento do Território e Energia, da Saúde e da Solidariedade, Emprego e Segurança Social - Diário da República - $1^{\text {a }}$ Série, № 253, 6644(2)-6644(9).

Rovelli, S., Cattaneo, A., Nuzzi C. P., Spinazzè, A., Piazza, S., Carrer, P., Cavallo, D. M., 2014. Airborne Particulate Matter in School Classrooms of Northern Italy. Int. J. Environ. Res. Public Health. 11, 1398-1421.

Sousa, S. I. V., Ferraz, C., Alvim-Ferraz, M. C. M., Vaz, L. G., Marques, A. J., Martins F. G., 2012a. Indoor air pollution on nurseries and primary schools: impact on childhood asthmastudy protocol. BMC Public Health. 12, 435.

Sousa, S. I. V., Alvim-Ferraz, M. C. M., Martins, F. G., 2012b. Indoor $\mathrm{PM}_{10}$ and $\mathrm{PM}_{2.5}$ at Nurseries and Primary Schools. Adv. Mater. Res. 433-440, 385-390.

Stanek, L. W., Sacks, J. D., Dutton, S. J., Dubois, J., 2011. Attributing health effects to apportioned components and sources of particulate matter. An evaluation of collective results. Atmos. Environ. 45, 5655-5663. 
Tippayawong N., Khuntong P., Nitatwichit C., Khunatorn Y., Tantakitti C., 2009.

500 Indoor/outdoor relationships of size-resolved particle concentrations in naturally ventilated

501 school environments. Build Environ. 44, 188-197.

502 Tong, S. T. Y., Lam K. C., 1998. Are nursery schools and kindergartens safe for our kids? The 503 Hong Kong study. Sci. Total Environ. 216, 217-225.

504 USEPA, 2012. The Inside Story: A Guide to Indoor Air Quality 505 http://www.epa.gov/iaq/pubs/insidestory.html. Assessed February 22, 2014.

506 WHO, 2010. WHO guidelines for indoor air quality: selected pollutants, World Health 507 Organisation, Regional office in Europe, European Series, Copenhagen, Denmark.

508 Wichmann, J., Lind, T., Nilsson, M.A.-M., Bellander, T., 2010. $\mathrm{PM}_{2.5}$, soot and $\mathrm{NO}_{2}$ indoor509 outdoor relationships at homes, pre-schools and schools in Stockholm, Sweden. Atmos. 510 Environ. 44, 4536-4544.

511 Yoon, C., Lee, K., Park, D., 2011. Indoor air quality differences between urban and rural 512 preschools in Korea. Environ. Sci. Pollut. R. 18, 333-345.

513 Zuraimi, M. S., Tham, K. W., 2008. Indoor air quality and its determinants in tropical child 514 care centres. Atmos. Environ. 42, 2225-2239. 